\title{
The Scientific Activities of Sir Charles Parsons
}

$\mathrm{T}$ HE second Parsons Memorial Lecture was delivered on November 25 last by Dr. Gerald Stoney at the Institution of Electrical Engineers. As Sir Frank Smith in the first of these lectures, given at Newcastle-upon-Tyne a year earlier, had dealt at length with the invention and application of the steam turbine, Dr. Stoney devoted his lecture to the less well-known activities of the great engineer. This was a subject for which he was pre-eminently fitted, for he was closely associated with Sir Charles Parsons during ideas were also largely influenced by noticing the analogy between the flow of steam under small differences of pressure and the flow of an incompressible fluid like water. At Heaton is preserved a model boat (Fig. 1) the propeller of which was driven by the action of compressed air. The screw propeller is fitted beneath the centre of the boat and is surrounded by a double shrouding carrying blades on which the jet of air impinged. It is evident, said Dr. Stoney, that this work led to the conception of the steam turbine.

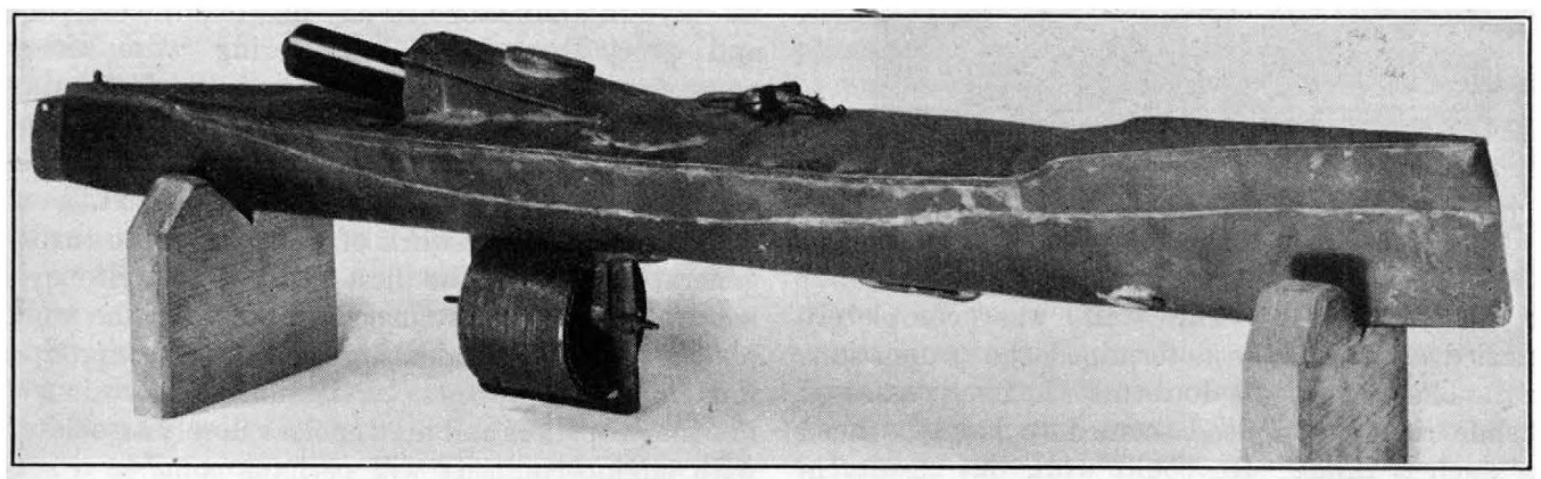

Fig. 1.

Model boat, designed by Sir Charles Parsons, driven by compressed air.

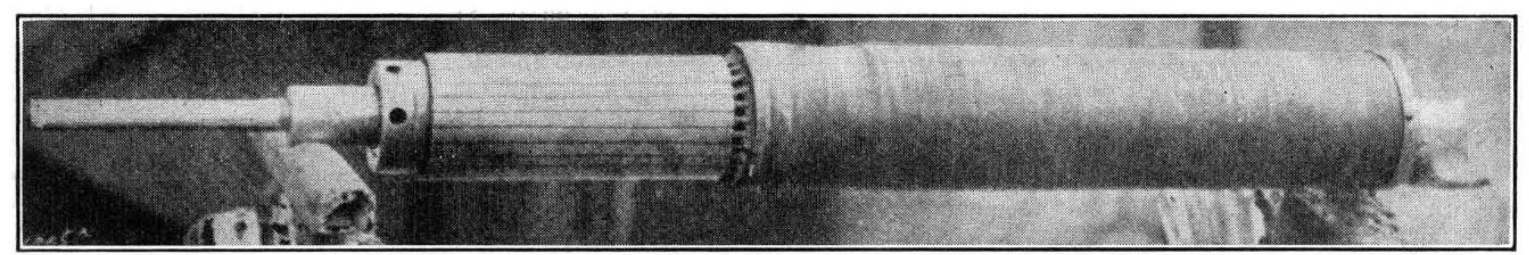

Fig. 2.

Armature of the first Parsons turbo-generator.

his most prolific period. Parsons himself once spoke of Dr. Stoney as having grown up with the Heaton Works of Messrs. C. A. Parsons and Co., but he was also closely connected with the work of the Parsons Marine Steam Turbine Co. Much of what he had to say was therefore of great historical interest.

The question may well be asked what led Parsons to the conception of the steam turbine. At the outset, Dr. Stoney answered this by recalling that, when quite a young man, Parsons was interested in the production of power from the kinetic energy of a jet of gas. His first efforts in this direction were applied to the development of torpedoes, which were driven by the kinetic energy of gases produced by the combustion of an explosive. His
Though he was influenced by analogies between the flow of steam and the flow of water, Parsons never told anyone, not even the most trusted members of his staff, how he arrived at the design of an actual machine for any given conditions. Possessing high mathematical ability, he was rarely, if ever, known to make use of formal mathematical reasoning for the solution of any problem. He had a thoroughly scientific mind and scientific habits of thought, and his results were the outcome of these, rather than of any deliberate calculations. In the early days, he would come into the office with a scrap of paper on which were written particulars of the blading he had decided upon for a certain turbine. These were set out to scale and modified if necessary according 


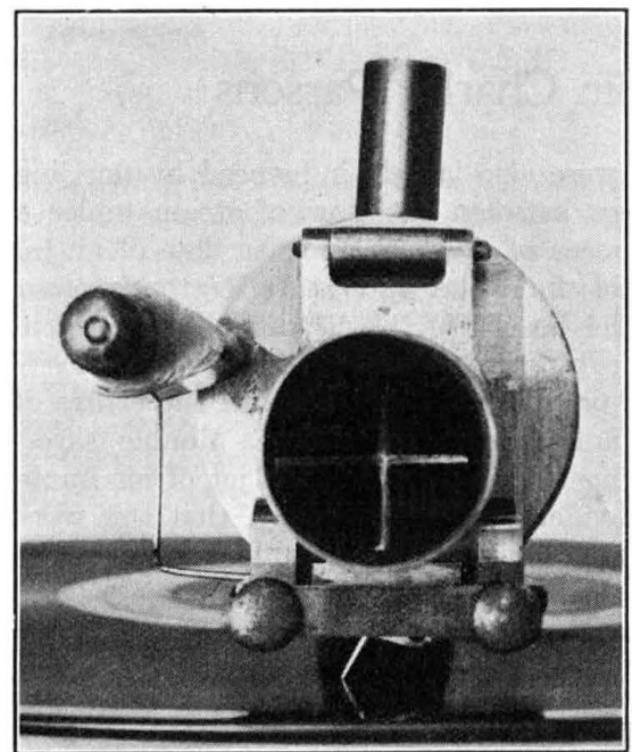

Fig. 3.

ThE AUXETOPHONE MOUNTED ON A GRAMOPHONE RECORD.

to his judgment. The staff was completely puzzled as to how he determined the proportions of the blading. It was doubtful if he ever possessed a slide rule, and indeed seemed to have no need for such a thing. He could work out results in his head or on paper as quickly as most people could obtain them on a slide rule, though he never explained the process and it is doubtful if he could have done so.

It never seemed to Parsons that his powers were exceptional. He had an extraordinary intuition on all matters connected with design. No matter how difficult or novel the problem, he seemed to know instinctively how to solve it. $\mathrm{He}$ also had great mechanical aptitude. He was perfectly familiar with all workshop processes, and had unusual skill with his hands. $\mathrm{He}$ took a delight in making models, not as ends in them. selves, but as a means of studying some problem.

It was in 1884 that Parsons made his first turbo-generator. This developed about $4 \frac{1}{2} \mathrm{kw}$. at 18,000 revolutions per minute. The dynamo had to be specially designed, for dynamos at that time revolved at about 1,200 revolutions per minute. The armature of this first turbogenerator (see Fig. 2) was only about $2 \frac{5}{8}$ in. in diameter. Every pound weight at the surface of it had a centrifugal force of about 5 tons at the normal speed of the machine, so great care had to be taken to make the construction sufficiently strong to resist mechanical stresses. Few better examples of Parsons's intuition, said Dr. Stoney, can be given than the fact that the proportions of his first turbo-dynamo, designed fifty-three years ago, when electrical knowledge was so rudimentary, could scarcely be improved upon to-day. After further references to the development of turbodynamos and turbo-alternators, Dr. Stoney remarked: "Some of the practices of these early days must now appear very primitive, but one must remember that Parsons was breaking new ground in almost every direction. Books such as we have in abundance to-day on steam, electricity and every branch of engineering were either non-existent or extremely elementary. Measuring instruments, as we know them to-day, did not exist and the range of materials for constructional and insulating purposes was very restricted."

The record of the work of Parsons on the turbogenerator formed the first half of Dr. Stoney's lecture, and he then turned to consider the work of Parsons on condensing plant, turbo pumps, fans and compressors, cavitation, the erosion of marine propellers and matters less closely associated with engineering. It will perhaps come as a surprise to many to learn that when Parsons was deeply immersed in his early study of the turbine and the dynamo, he should have turned to the manufacture of electric lamps. In 1885, when a partner in the firm Clarke, Chapman, Parsons and Co., he founded the Sunbeam Lamp Company, making arc lamps and incandescent lamps At

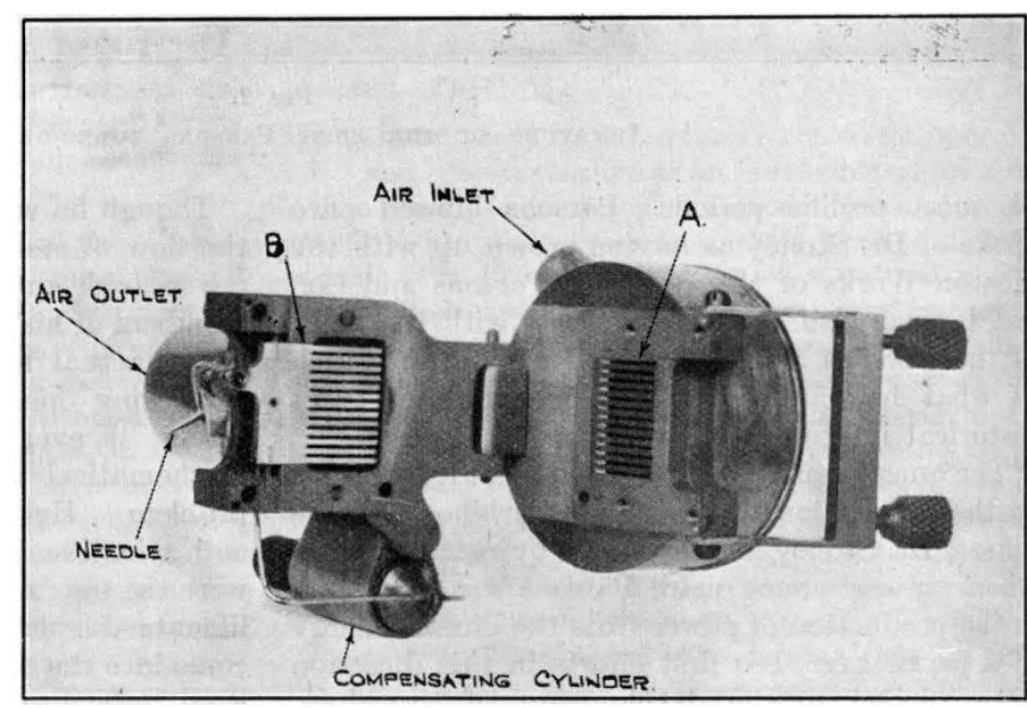

Fig. 4.

THE AUXETOPHONE OPENED TO SHOW PARTS. 
first small lamps were made, but after a legal decision in a patent action that a 'filament' was less than $\frac{1}{32}$ in. in diameter, the Company restricted itself to the production of lamps having 'carbons', not 'filaments', of $\frac{1}{32}$ to $\frac{1}{8}$ in. diameter. The lamps ranged from 100 to 3000 c.p. At the Newcastle Exhibition of 1887, lamps made by the Sunbeam Co. were used for lighting, the current being supplied by ten Parsons turbo-dynamos ranging from $16 \mathrm{kw}$. to $32 \mathrm{kw}$. in capacity. Little information has been preserved as to the processes used in the manufacture of the lamps, but the material for the carbons appears to have consisted of tar, a special anthracite and zirconium.

To the same early period-the 'eighties-belongs the early optical work of Parsons, which began with the manufacture of parabolic mirrors for searchlights. He devised a process for bending the glass while hot in an accurately figured castiron mould, and his methods are used to-day with very little alteration. Several hundred mirrors per month are now turned out at Heaton for searchlights and other purposes. He had always a liking for optical work, no doubt inherited from his father, the Earl of Rosse, whose $6 \mathrm{ft}$. telescope at Birr was the wonder of the astronomical world. After the Great War, Parsons purchased the optical glass works set up by the Government near Derby and acquired a controlling interest in the firm of Messrs. Ross, Ltd. A year or two later he acquired the works of Sir Howard Grubb at St. Albans, and forming the firm of Sir Howard Grubb, Parsons and Co., Ltd., founded new works at Walker Gate, close to the Heaton Works, and it was there the 74-in. telescope for Toronto, the largest in the British Empire, was built.

Parsons's interest in other scientific matters was shown by his suggestion for a very deep bore hole, his experiments on the artificial production of diamonds, his experiments on the compressibility of liquids and his invention of the auxetophone. About 1902, when phonographs and gramophones were becoming popular, he realized that their reproduction of sound was far from satisfactory. He therefore decided to make a reproducer worked by compressed air by which the sound waves should be generated more in accordance with the action of an organ pipe than that of a telephone receiver. Then followed experiments on the flow of air and trials with various types of valves which could be controlled by the needle of the gramo. phone. Figs. 3 and 4 show the auxetophone mounted above a gramophone record, and open to show the valve and its seating. The moving part of the valve, about $\frac{1}{2}$ in. by $\frac{3}{4}$ in., was a flat comb of magnalium. Air at about $2 \mathrm{lb}$. per square inch was supplied to the wind-box through a flexible tube. Such a valve, said Dr. Stoney, made thirty-five years ago, reproduced sound with a volume and quality which have only recently been equalled by wireless loudspeakers and electric gramophones. The auxetophone was also applied to musical instruments, and was used with success in the orchestra at the Queen's Hall, London, in 1906. The invention of this instrument was entirely the work of Parsons's leisure hours, just at the time he was engaged in the application of steam turbines to naval vessels and fast mercantile ships.

\title{
Heat Production, Nutrition, and Growth in Man: Some New Views*
}

\author{
By Dr. E. P. Poulton
}

\section{Constancy of Carbon Dioxide}

Series of basal metabolism observations on the same individual have been published by a number of observers, and analysis shows that when the previous diet did not contain much carbohydrate the carbon dioxide tended to remain more constant than did the oxygen, which fell as the quotient rose. When the previous diet was rich in carbohydrate there was a tendency for the carbon dioxide to rise. It will be shown that a constant carbon dioxide as shown in Figs. $1 a$ and $1 b$ is in favour of the theory of the constant combustion ratio, and, such being the case, further observations

\footnotetext{
*Continued from p. 147.
}

would be desirable to prove definitely the relation of this constancy to the diet taken. According to this theory, the carbohydrate and fat are always burnt in a fixed ratio corresponding to a quotient of about 0.8 , and if the quotient is higher there is a simultaneous conversion of carbohydrate to fat and if lower a conversion in the opposite direction. Such a theory cannot be proved by metabolic determinations on the whole organism between the respiratory quotients for the combustion of pure fat and pure carbohydrate, because it would make no difference whether with a higher quotient a higher proportion of carbohydrate was burnt or whether the same amount was burnt as before and the extra amount disappeared by being 